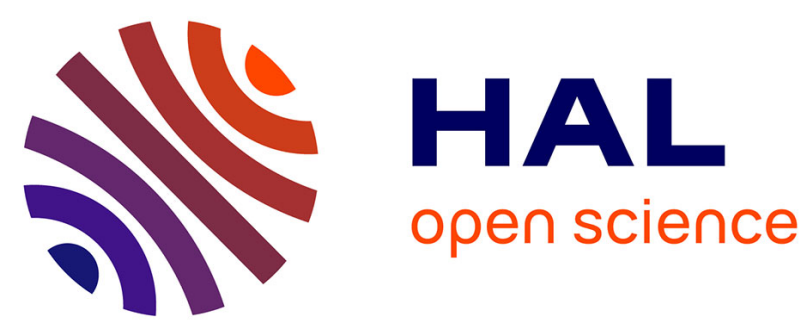

\title{
TH1 and TH2 cell polarization increases with aging and is modulated by zinc supplementation
}

\author{
Peter Uciechowski, Laura Kahmann, Birgit Plümäkers, Marco Malavolta, \\ Eugenio Mocchegiani, George Dedoussis, Georges Herbein, Jolanta Jajte, \\ Tamas Fulop, Lothar Rink
}

\section{To cite this version:}

Peter Uciechowski, Laura Kahmann, Birgit Plümäkers, Marco Malavolta, Eugenio Mocchegiani, et al.. TH1 and TH2 cell polarization increases with aging and is modulated by zinc supplementation. Experimental Gerontology, 2008, 43 (5), pp.493. 10.1016/j.exger.2007.11.006 . hal-00499037

\section{HAL Id: hal-00499037 https://hal.science/hal-00499037}

Submitted on 9 Jul 2010

HAL is a multi-disciplinary open access archive for the deposit and dissemination of scientific research documents, whether they are published or not. The documents may come from teaching and research institutions in France or abroad, or from public or private research centers.
L'archive ouverte pluridisciplinaire HAL, est destinée au dépôt et à la diffusion de documents scientifiques de niveau recherche, publiés ou non, émanant des établissements d'enseignement et de recherche français ou étrangers, des laboratoires publics ou privés. 


\section{Accepted Manuscript}

TH1 and TH2 cell polarization increases with aging and is modulated by zinc supplementation

Peter Uciechowski, Laura Kahmann, Birgit Plümäkers, Marco Malavolta, Eugenio Mocchegiani, George Dedoussis, Georges Herbein, Jolanta Jajte, Tamas Fulop, Lothar Rink

PII:

S0531-5565(07)00273-2

DOI: 10.1016/j.exger.2007.11.006

Reference: EXG 8417

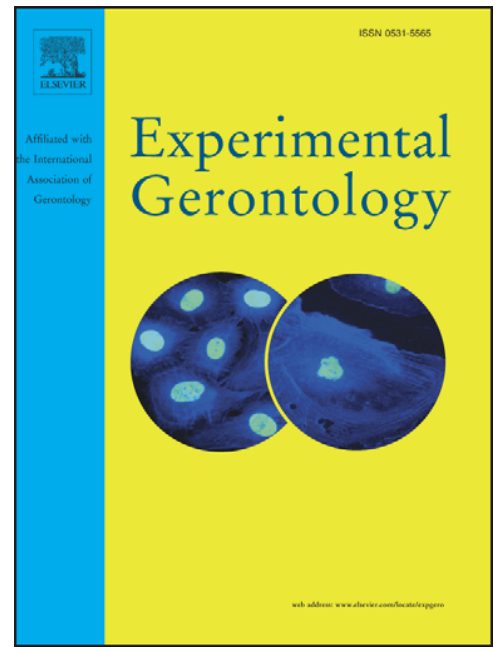

To appear in:

Experimental Gerontology

Received Date:

12 September 2007

Revised Date:

16 November 2007

Accepted Date:

20 November 2007

Please cite this article as: Uciechowski, P., Kahmann, L., Plümäkers, B., Malavolta, M., Mocchegiani, E., Dedoussis, G., Herbein, G., Jajte, J., Fulop, T., Rink, L., TH1 and TH2 cell polarization increases with aging and is modulated by zinc supplementation, Experimental Gerontology (2007), doi: 10.1016/j.exger.2007.11.006

This is a PDF file of an unedited manuscript that has been accepted for publication. As a service to our customers we are providing this early version of the manuscript. The manuscript will undergo copyediting, typesetting, and review of the resulting proof before it is published in its final form. Please note that during the production process errors may be discovered which could affect the content, and all legal disclaimers that apply to the journal pertain. 


\section{TH1 and TH2 cell polarization increases with aging and is modulated by zinc supplementation}

Running title: Zinc modulates age-associated T helper cell polarization

Peter Uciechowski ${ }^{\mathrm{a}}$, Laura Kahmann ${ }^{\mathrm{a}}$, Birgit Plümäkers ${ }^{\mathrm{a}}$, Marco Malavolta ${ }^{\mathrm{b}}$, Eugenio Mocchegiani ${ }^{\mathrm{b}}$, George Dedoussis ${ }^{c}$, Georges Herbein ${ }^{\mathrm{d}}$, Jolanta Jajte ${ }^{\mathrm{e}}$, Tamas Fulop ${ }^{\mathrm{f}}$, Lothar Rink ${ }^{\mathrm{a}}{ }^{*}$

a Institute of Immunology, University Hospital, RWTH Aachen University, Aachen, Germany

${ }^{\mathrm{b}}$ Immunology Centre (Section Nutrition, Immunity and Ageing), Research Department, INRCA (Italian National Research Centres on Ageing), Ancona, Italy

${ }^{c}$ Department of Nutrition, Science and Dietetics, Harokopio University, Athens, Greece

${ }^{\mathrm{d}}$ Department of Virology, IFR 133, EA 3186, Franche-Comte University, Besançon, France

${ }^{\mathrm{e}}$ Department of Toxicology, Division of Toxicology and Food Analysis, Faculty of Pharmacy, Medical University of Lodz, Lodz, Poland

${ }^{\mathrm{f}}$ Research Center on Aging, Immunology Program, Geriatric Division, Faculty of Medicine, University of Sherbrooke, Québec, Canada

* Corresponding author:

Prof. Dr. Lothar Rink

Institute of Immunology

RWTH Aachen University Hospital

Pauwelsstr. 30

D-52074 Aachen

Germany

Phone: $\quad+492418080208$

Fax: $\quad$ +492418082613

E-mail: $\quad$ LRink@ukaachen.de

\section{Key words:}

Activated T cells, CCR4/CCR5 ratio, elderly, serum zinc level, TH1/TH2 balance, zinc deficiency, zinc supplementation 


\section{Abstract:}

Elderly subjects suffer from increased levels of activated T cells and a TH1/TH2 imbalance. Zinc deficiency of the aged is correlated with decreased cell-mediated immune responses. The association of age and zinc adjustment with the amounts of TH1 (CCR5+) and TH2 (CCR4+) cell populations in healthy aged old donors enrolled in the European ZINCAGE project was examined. Old and nonagenarian individuals revealed increased TH1, TH2 cell numbers and a decreased TH2/TH1 ratio in comparison to young individuals. The differences between TH2/TH1 ratios of young and old/nonagenarians arose from young females. Adjusted zinc status led to enhanced TH2 and TH1 amounts in fresh whole blood and thawed cells of aged donors whereas increased HLA-DR+ expression and a generally lower CCR5 expression was observed on thawed PBMC. In conclusion, aging is associated with an increase in T helper cell polarization, and changes in TH2/TH1 subsets are more obvious in women than in men. Advanced healthy aging is accompanied by TH cell polarization, too. Moderate zinc supplementation in vivo alters TH proportions. Longer zinc treatment will give more insight into the beneficial effect of zinc on T helper cell modulation.

\section{Introduction:}

Zinc is an essential trace element involved in transcription, replication, and signal transduction (Dardenne 2002; Ibs et al., 2003). Mild zinc deficiency occurs more frequently than severe deficiency and is a commonly found in healthy elderly subjects resulting in impaired cell-mediated immune responses (Ibs et al., 2003).

The clinical consequences of zinc deficiency are thymic atrophy, enhanced number of infections and autoimmune diseases (Prasad 2004). Although zinc deficiency reduces the functions of neutrophils, monocytes and B cells (Wellinghausen et al., 1997), the T cell compartment is mainly affected by both decreased and increased serum levels of zinc (Cakman et al., 1996; Prasad 2000). Additionally, zinc deficiency causes a functional alteration in $\mathrm{TH} 1$ and $\mathrm{TH} 2$ subsets, resulting from impaired synthesis of the TH1 cytokines IFN- $\gamma$ and IL-2, whereas TH2 cytokines IL-4, IL-6 and -10 remain unchanged (Prasad 2000; Dardenne 2002).

In the elderly, changes in all parts of the immune system can be observed, designated as immunosenescence (Pawelec et a., 2002), leading to enhanced incidence of infection, cancer and autoimmune diseases (Ginaldi et al., 2005; Pawelec et al., 2006). In contrast, elderly subjects reveal insufficient intake of zinc and build a group with high risk of zinc deficiency (Kaplan et al., 1988; Ibs et al., 2003). Therefore, zinc supplementation may 
studies are important to determine the restoration of immune response of elderly people by balancing the zinc status (Haase et al., 2006). Alterations during aging mainly affect the $\mathrm{T}$ cell system resulting in a reduction of naive $\mathrm{T}$ cells and an increase in memory or effector-memory cells, a decrease in function, signalling, and shifts in T cell subsets (Lesourd 1997; Prasad 2000; Pawelec et al., 2002; Mocchegiani et al., 2004). T cells of elderly subjects display a non-specific pre-activation, e.g. shown by increased CD25+ T cell amounts (Pawelec et al., 2002), resulting in impaired immune functions and responses to vaccination (Huang et al., 1992).

In this study we investigated the influence of zinc and age in modifying TH-subpopulations.

\section{Materials and Methods:}

\subsection{Young and elderly donors:}

A total of 60 (31 women, 29 men) physically and mentally healthy elderly volunteers aged 65-82 years (mean age of 74.2; SD: \pm 5.6 years) were recruited in France, Germany, Greece, Italy and Poland and designated as the old group. The second group $(n=15 ; 6$ women, 9 men) consisted of individuals with a mean age of 91.4; $\mathrm{SD}: \pm 3.5$ years, named nonagenarians. 15 frozen PBMC samples, 8 from Germany and 7 from Italy, were tested before and after zinc supplement ( 9 women, 6 men; mean age of 71.3; SD: \pm 6.3 years). The members of this third group displayed mild zinc deficiency before supplementation with a mean of $10.58 \mu \mathrm{M}$; SD: \pm 2.09 serum zinc levels which was adjusted to a mean of $12.59 \mu \mathrm{M}$; SD: $\pm 1.96(\mathrm{p}=0.015)$ after seven weeks of zinc supplementation. The physiological normal zinc concentration in serum ranges between 12-16 $\mu \mathrm{M}$ (Rink et al., 2000). The serum zinc levels were determined by induction plasma coupled mass spectrometry as described previously (Kahmann et al., 2006). Additionally, whole blood lymphocytes of 20 healthy elderly individuals (mean $68.5 \pm 4.98$ years; 10 women, 10 men) before and after zinc treatment were analyzed immediately after taking the blood samples. Probes of two probands could not be analyzed at both time points and were therefore skipped from the analysis. All individuals of the four groups had to fulfil qualification and selection criteria required by the European specific targeted research project ZINCAGE (www.zincage.org). The exclusion criteria and zinc treatment have been described (Kahmann et al., 2006). The young control group consisted of 6 healthy female and 5 male donors with a mean age of 31.8; SD: \pm 7.6 years. 
Peripheral blood mononuclear cells (PBMC) were isolated as previously described (Haase et al., 2006). PBMCs at a concentration of $5 \times 10^{6}$ cells $/ \mathrm{ml}$ were cyropreserved in freezing medium $(90 \%$ heat-inactivated lowendotoxin fetal calf serum (FCS) (PAA Laboratories, Linz, Austria) and 10 \% DMSO) and stored overnight at $80^{\circ} \mathrm{C}$ before transfer into liquid nitrogen. For analysis, the cells were thawed in a water bath at $37^{\circ} \mathrm{C}$ and washed twice in PBS containing $20 \%$ FCS. Viability was tested by propidium iodine staining.

\subsection{Analyses of T cell subsets and activation marker expression}

Alterations in TH1/TH2 subsets were determined by the detection of appropriate chemokine receptors due to preferential expression of CCR4 on human TH2 cells and CCR5 on human TH1 cells (Bonecchi et al., 1998). Immunophenotyping of whole blood was performed as described previously (Kahmann et al., 2006).

PBMC were stained with monoclonal antibodies against CD3, CD4, CCR4, CCR5 and HLA-DR surface molecules including appropriate isotypic controls (all from BD Bioscience, Heidelberg, Germany). The stained cells were analyzed by two-colour fluorescence in a lymphocyte gate using a FACS calibur (BD Biosciences).

\subsection{Statistical methods}

Experimental data are expressed as means \pm standard error. The Wilcoxon test performed to determine the significance of difference for paired samples and Spearman correlation were analyzed with the program SPSS 12.0 (SPSS Inc., Germany).

\section{Results:}

\subsection{The number of TH1 and TH2 polarized cells increases with age}

It is known from many studies that TH1 and TH2 cytokines are found to be imbalanced during aging (Cakman et al., 1996; Prasad 2000). When compared to lymphocytes of young individuals $(n=11)$, healthy old $(p=0.003$; $\mathrm{n}=60)$ and nonagenarian $(\mathrm{p}=0.004 ; \mathrm{n}=15)$ subjects displayed significantly higher amounts of CD3+CCR4+ cells. Especially nonagenarians had higher percentages of CD3+CCR4+ TH2 cells than measured in the young and old group. A significant increase of the percentage of CD3+CCR5+ TH1 cells in healthy old $(\mathrm{p}=0.004)$ and nonagenarians $(\mathrm{p}=0.026)$ subjects compared to healthy young individuals could also been detected (data not 
1) compared to younger subjects and nonagenarians.

We also addressed the question of whether gender influences TH1/TH2 levels during aging since sexual hormones such as estrogens and progesterone are described to positively affect the TH2 subpopulation (GironGonzalez et al., 2000). By analyzing the young group, we detected a significantly higher proportion of TH2 $(\mathrm{CD} 3+\mathrm{CCR} 4+)$ cells $(\mathrm{p}=0.043)$, a reduced percentage of TH1 (CD3+CCR5+) cells and a higher CCR4/CCR5 ratio $(p=0.043)$ in young females than in males (data not shown). When comparing the CCR4/CCR5 ratio in women and men of the young $(6 \mathrm{f}, 5 \mathrm{~m})$, old $(31 \mathrm{f}, 29 \mathrm{~m})$, and nonagenarian $(6 \mathrm{f}, 9 \mathrm{~m})$ groups, a significant enhancement of CCR4/CCR5 ratio to old $(p=0,028)$ and nonagenarian $(p=0.046)$ subjects could only be observed in young women (data not shown). However, the comparison of females and males from both the old and nonagenarian group did not show any differences in the percentage of CD3+CCR4+, CD3+CCR5+ cells and the CCR4/CCR5 ratio. Thus, an age-dependent change in TH1 and TH2 subsets took place in women which might result from altered sexual hormone production.

\subsection{Modulation of T cell subsets during zinc supplementation}

Zinc deficiency has been described to influence the balance of TH1/TH2 T helper cell subsets (Prasad 2000; 2006). Observing only a slight but not significant change in the CCR4/CCR5 ratio after zinc supplementation (Kahmann et al., 2006) in a small number of aged individuals, we increased the number of analyses in our own laboratories as well as using frozen PBMC from the ZINCAGE consortium. We investigated the amounts of TH1 and TH2 cells of thawed PBMC from healthy elderly donors with mild zinc deficiency (serum zinc levels: mean $10.58 \mu \mathrm{M}$; SD: \pm 2.09$)$ significantly adjusted to $12.59 \mu \mathrm{M} ; \mathrm{SD}: \pm 1.96$ after seven weeks of zinc supplementation by flow cytometry. In comparison, we also analyzed fresh whole blood lymphocytes from healthy elderly individuals with mild zinc deficiency before $(11.15 \pm 1.77 \mu \mathrm{M})$ and increased zinc levels after treatment $(12.14 \pm 1.44 \mu \mathrm{M})$ under the same conditions. Figure 2A and 2B displays representative two-colour fluorescence stainings of frozen PBMC and whole blood lymphocytes. We found a significant increase of TH2

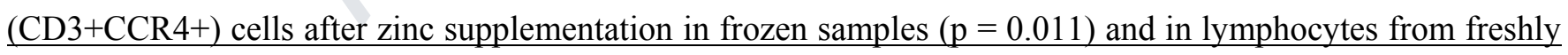
drawn blood $(\mathrm{p}=0.048)$. The same but not significant tendency was observed in TH1 cells, whereas an increased TH2/TH1 ratio in frozen PBMC in contrast to freshly analyzed lymphocytes after zinc adjustment 
frozen samples declined one third in contrast to freshly analyzed $\mathrm{T}$ cells. Therefore, the phenotypic analyses of frozen samples isolated from untreated and treated elderly subjects should be carefully assessed in the design of each in vivo study since isolation of PBMC and freezing-thawing procedures alter the proportions of lymphocyte subsets, their functional properties, or the expression of surface molecules such as CCR5 (Costantini et al., 2003). Consequently, the CCR4/CCR5 ratio shows an inverse tendency in frozen and fresh blood samples (Figure 3). A significant accumulation of CD4+HLA-DR+ cells after zinc supplementation (data not shown) within the frozen Italian samples could also be detected.

\section{Discussion}

By investigating the effect of age on the proportion of $\mathrm{T}$ helper subsets in frozen-thawed PBMC we found a significantly higher proportion of $\mathrm{TH} 1$ and $\mathrm{TH} 2$ cells in the old and in the nonagenarian group when compared to young individuals. These results are in line with other publications reporting mainly an enhancement of TH2 in elderly people (Cakman et al., 1996, Prasad 2000; Sandmand et al., 2002; Ibs et al., 2003). We analyzed TH subsets by staining CCR4 and CCR 5 described to be related to TH1 and TH2 cells (De et al., 2005, King et al., 2006; Yanai et al., 2007) Although other laboratories characterized TH1 and TH2 responses via intracellular IFN- and IL-4 cytokine staining after stimulation, there are also some drawbacks such as culturing and activation of lymphocytes, variation in viability when comparing frozen samples from different laboratories, reduced cytokine production (IL-2, IFN-), and altered T cell signal transduction within the elderly (Cakman et al., 1996; Pawelec et al., 2002; Linton and Dorshkind, 2004). Interestingly, the amounts of TH1 cells of nonagenarians were lower than those of the old subjects in contrast to higher TH2 amounts, and a change in the TH2/TH1 ratio compared to younger subjects could not be observed. Sandmand and coworkers (2002) also studied frozen samples and found that 81-year old individuals also showed a significant higher percentage of IFN- + T cells and IL-4+ T cells than the young control group. Additionally, they detected that centenarians had lower amounts of IFN- + CD8+ cell than the 81-year group, and that there was no difference in percentages of IFN- + CD4+ cells and IFN- +/IL-4+ ratio in comparison to young subjects. Furthermore, Alberti et al. (2006) found IL-4 positive cells significantly increased in activated/memory CD4+ subset from nonagenarians. We 
than in the old group which resulted in a significant difference in the TH2/TH1 ratio compared to the old group. This indicates that healthy aging is accompanied with the recurrence of TH1 and TH2 levels found in healthy young individuals.

On the other hand, the significant shifts to increased TH2 and TH1 counts in old and nonagenarians we detected resulted from the modification of the $\mathrm{TH} 2 / \mathrm{TH} 1$ subsets of women during aging. It is reported that women present a predominant TH2 cytokine profile (Giron-Gonzalez et al., 2000), that progesterone and B-estradiol induced production of IL-4 and IL-13 in human PBMC but not IFN- (Hamano et al. 1998) and that sexual steroids are capable of driving the balance towards TH1 or TH2 mediated responses (Whitacre et al., 1999). Scheffer et al. (2000) detected a variable production of the TH1 cytokine IFN- in young women but stable levels with increasing age while others observed increasing TH1 cytokine levels in postmenopausal women (Kamada et al., 2001). Therefore, the impact of altered levels of sexual hormones during the aging process together with the postmenopausal stages of women should be taken into account for further investigations of $\mathrm{T}$ helper subsets in immune gerontological studies.

Additionally, the effect of oral zinc supplementation on $\mathrm{TH} 1$ and $\mathrm{TH} 2$ subsets and $\mathrm{T}$ cell activation status of elderly subjects with moderate zinc deficiency were analyzed on freshly drawn whole blood and frozen PBMC. The shift of $\mathrm{TH} 1$ and $\mathrm{TH} 2$ subsets in healthy elderly individuals to a predominant $\mathrm{TH} 2$ response is due to impaired production of IFN- combined with an increased production of IL-4 and IL-10 after stimulation (Cakman et al., 1996; Rink et al., 1998). Zinc deficiency is also accompanied by TH1/TH2 imbalance resulting in increased susceptibility to infections. Beck et al. (1997) reported that the production of IL-2, IFN- $\gamma$ and TNF$\alpha$ by TH1 cells was decreased, whereas the levels of TH2 cytokines IL-4, -6 and -10 were unaffected during zinc deficiency. However, normalization or enhancement of TH1 cytokines IL-2 and IFN- production via zinc supplementation has been described (Prasad 2000, Kahmann et al. in press).

Therefore, this implies that zinc treatment would affect the proportions of TH1 and TH2 cells. We could demonstrate an increase of TH1 and TH2 cells in thawed samples and whole blood lymphocytes but a slight $\underline{\text { reduction in TH2/TH1 ratio after zinc supplementation in fresh whole blood lymphocytes only. Although zinc }}$ treatment leading to physiological serum levels did not significantly affect the TH2/TH1 ratio in the elderly 
zinc influences the TH2/TH1 balance. Zinc treatment might also lead to correction of $\mathrm{T}$ cell responses since we detected a higher IFN- release from activated T cells after zinc supplementation (Kahmann et al. in press). Since the period of zinc supplementation might have been too short, supplementation of up to at least three months might uncover modifications in the TH2/TH1 ratio due to sufficient production of naive $\mathrm{T}$ cells. The generation of naive $\mathrm{T}$ cells, which can alter the ratio, is also hampered by increased amounts of memory cells in the elderly (Ibs et al., 2003).

Thawed PBMC showed a lower CCR5 expression and an enhanced TH2/TH1 ratio in comparison to fresh whole blood. Separation of PBMC via Ficoll density gradient centrifugation and cryopreservation led to $\underline{\text { selective loss or increase of } \mathrm{T} \text { cell subsets or to an increase in the proportion of HLA-DR+ cells (Tollerud et al., }}$ 1991) as well as a decline in CCR5 expression in comparison to whole blood analysis techniques (Romeu 1992; $\underline{\text { Renzi and Ginns 1997, Costantini et al., 2003). Further comparative experiments with an elevated number of }}$ markers and cytokine staining of whole blood cells and frozen samples have to be performed to determine the role of CCR markers in zinc treatment and $\mathrm{TH} 1 / \mathrm{TH} 2$ balance in the elderly. This will also help to determine the impact of frozen material in routine monitoring or in the design of multicenter studies.

In conclusion our study shows that the increase of TH1 and TH2 cells as well as TH2/TH1 ratio is associated with age and with gender. It could also be shown that the increased $\mathrm{TH}$ levels were lower in nonagenarians than in old subjects suggesting that healthy aging is related with a less pronounced TH cell polarization.

However, zinc supplementation modulates the TH2 polarization resulting in an increase of the TH2 and TH1 population which is normally observed in healthy aged nonagenarians. Longer zinc treatment periods in combination with the examination of fresh whole blood will show the impact of zinc affecting the TH2/TH1 balance. Therefore, we would suggest that moderate zinc supplementation is helpful for healthy aging, which should be further proven in future studies. 
This study was supported in part by the EU project ZINCAGE (Food-CT-2003-506850). We thank Ms. Romney Haylett for critical reading of the manuscript.

\section{References}

Alberti, S., Cevenini, E., Ostan, R., Capri, M., Salvioli, S., Bucci, L., Ginaldi, L., De Martinis, M., Franceschi, C., Monti, D., 2006. Age-dependent modifications of Type 1 and Type 2 cytokines within virgin and memory CD4+ T cells in humans. Mech. Ageing Dev. 127, 560-566.

Beck, F.W., Prasad., A.S., Kaplan, J., Fitzgerald, J.T., Brewer G.J., 1997. Changes in cytokine production and T cell subpopulations in experimentally induced zinc-deficient humans. Am. J. Physiol. 272, E1002-E1007.

Bonecchi, R., Bianchi, G., Bordignon, P.P., D'Ambrosio, D., Lang, R., Borsatti, A., Sozzani, S., Allavena, P., Gray, P.A., Mantovani, A., Sinigaglia, F., 1998. Differential expression of chemokine receptors and chemotactic responsiveness of type $1 \mathrm{~T}$ helper cells (Th1s) and Th2s. J. Exp. Med. 187, 129-134.

Boukaiba, N., Flament, C., Acher, S., Chappuis, P., Piau, A., Fusselier, M., Dardenne, M., Lemonnier, D. 1993. A physiological amount of zinc supplementation: effects on nutritional, lipid, and thymic status in an elderly population. Am. J. Clin. Nutr.57, 566-572.

Cakman, I., Rohwer, J., Schutz, R.M., Kirchner, H., Rink, L. 1996. Dysregulation between TH1 and TH2 T cell subpopulations in the elderly. Mech. Ageing Dev. 87, 197-209.

Costantini, A., Mancini, S., Giuliodoro, S., Butini, L., Regnery, C.M., Silvestri, G., Montroni, M. 2003. Effects of cryopreservation on lymphocyte immunophenotype and function. J. Immunol. Methods 278, 145-155.

Dardenne, M., 2002. Zinc and immune function. Eur. J. Clin. Nutr. 56, Suppl 3, 20-23.

De A.K., Miller-Graziano, C.L., Calvano, S.E., Laudanski, K., Lowry, S.F., Moldawer, L.L., Remick, D.G. Jr, Rajicic, N., Schoenfeld, D. Tompkins RG. 2005. Selective activation of peripheral blood T cell subsets by endotoxin infusion in healthy human subjects corresponds to differential chemokine activation. J. Immunol. 175, 6155-6162.

Ginaldi, L., De Martinis, M., Monti, D., Franceschi, C., 2005. Chronic antigenic load and apoptosis in immunosenescence. Trends Immunol. 26, 79-84.

Giron-Gonzalez, J.A., Moral, F.J., Elvira, J., Garcia-Gil, D., Guerrero, F., Gavilan, I., Escobar, L., 2000. Consistent production of a higher TH1:TH2 cytokine ratio by stimulated T cells in men compared with women. Eur. J. Endocrinol. $143,31-36$.

Haase, H., Hebel, S., Engelhardt, G., Rink, L., 2006. Flow cytometric measurement of labile zinc in peripheral blood mononuclear cells. Anal. Biochem. 352, 222-230.

Hamano, N., Terada, N., Maesako, K., Hohki, G., Ito, T., Yamashita, T., Konno, A., 1998. Effect of female hormones on the production of IL-4 and IL-13 from peripheral blood mononuclear cells. Acta Otolaryngol. Suppl. 537,27-31.

Huang, Y.P., Pechere, J.C., Michel, M., Gauthey, L., Loreto, M., Curran, J.A., Michel, J.P., 1992. In vivo T cell activation, in vitro defective IL-2 secretion, and response to influenza vaccination in elderly women. J. Immunol. 148, 715-722.

Ibs, K.H., Gabriel, P., Rink, L., 2003. Zinc and the immune system of elderly. Advances in Cell Aging and Gerontology $13,243-253$.

Kahmann, L., Uciechowski, P., Warmuth, S., Malavolta, M., Mocchegiani, E., Rink L., 2006. Effect of improved zinc status on T helper cell activation and TH1/TH2 ratio in healthy elderly individuals. Biogerontology 7, 429-435.

Kahmann, L. Uciechowski, P., Warmuth, S., Plümäkers, B., Gressner, A.M., Malavolta, M., Mocchegiani, E., Rink L. 2007. Zinc supplementation in the elderly reduces spontaneous inflammatory cytokine release and restores T cell functions. Rejuvenation Res., in press. 
Kamada, M., Irahara, M., Maegawa, M., Ohmoto, Y., Murata, K., Yasui, T., Yamano, S., Aono, T., 2001. Transient increase in the levels of T-helper 1 cytokines in postmenopausal women and the effects of hormone replacement therapy. Gynecol. Obstet. Invest. 52, 82-88.

Kaplan, J., Hess, J.W., Prasad, A.S., 1988. Impaired Interleukin-2 Production in the Elderly: Association With Mild Zinc Deficiency. The Journal of Trace Elements in Experimental Medicine 1, 3-8.

King, M.R., Ismail, A.S., Davis, L.S., Karp, D.R. 2006. Oxidative stress promotes polarization of human T cell differentiation toward a T helper 2 phenotype. J. Immunol.176, 2765-2772.

Lesourd, B.M., 1997. Nutrition and immunity in the elderly: modification of immune responses with nutritional treatments. Am. J. Clin. Nutr. 66, 478S-484S.

Linton, P.J., Dorshkind, K. 2004. Age-related changes in lymphocyte development and function. Nat. Immunol. 5, 133139.

Mocchegiani, E., Giacconi, R., Cipriano, C., Muti, E., Gasparini, N., Malavolta, M., 2004. Are zinc-bound metallothionein isoforms (I+II and III) involved in impaired thymulin production and thymic involution during ageing? Immun. Ageing. 12, 1-5.

Pawelec, G., Barnett, Y., Forsey, R., Frasca, D., Globerson, A., McLeod, J., Caruso, C., Franceschi, C., Fulop, T., Gupta, S., Mariani, E., Mocchegiani, E., Solana, R.,2002. T cells and aging, January 2002 update. Front. Biosci. 7, d1056-183.

Pawelec, G., Koch, S., Franceschi, C., Wikby, A., 2006. Human immunosenescence: does it have an infectious component? Ann. N. Y. Acad. Sci. 1067, 56-65.

Prasad, A.S., 2000. Effects of zinc deficiency on Th1 and Th2 cytokine shifts. J. Infect. Dis. 182, Suppl 1, S62-68.

Prasad, A.S., 2004. Zinc deficiency: its characterization and treatment. Met. Ions Biol. Syst. 41, 103-137.

Renzi, P., Ginns, L.C., 1987. Analysis of T cell subsets in normal adults. Comparison of whole blood lysis technique to Ficoll-Hypaque separation by flow cytometry. J. Immunol. Methods 98, 53-56.

Rink, L., Cakman, I., Kirchner, H., 1998. Altered cytokine production in the elderly. Mech. Ageing Dev. 102, 199-209.

Rink, L., Gabriel, P., 2000. Zinc and the immune system. Proc. Nutr. Soc. 59, 541-552.

Romeu, M.A., Mestre, M., Gonzalez, L., Valls, A., Verdaguer, J., Corominas, M., Bas, J., Massip, E., Buendia, E., 1992. Lymphocyte immunophenotyping by flow cytometry in normal adults. Comparison of fresh whole blood lysis technique, Ficoll-Paque separation and cryopreservation. J. Immunol. Methods 154; 7-10.

Sandmand, M., Bruunsgaard, H., Kemp, K., Andersen-Ranberg, K., Pedersen, A.N., Skinhoj, P., Pedersen, B.K., 2002. Is ageing associated with a shift in the balance between Type 1 and Type 2 cytokines in humans? Clin. Exp. Immunol. 127, 107-114.

Scheffer, C., Zawatzky, R., Rink, L., 2000. Interferon-gamma (IFN-gamma) levels finally become stable with increasing age as revealed by using an ELISA corresponding to the bioactivity. Mech. Ageing Dev. 121, 47-58.

Tollerud, D.J., Brown, L.M., Clark, J.W., Neuland, C.Y., Mann, D.L., Pankiw-Trost, L.K., Blattner, W.A., 1991. Cryopreservation and long-term liquid nitrogen storage of peripheral blood mononuclear cells for flow cytometry analysis: effects on cell subset proportions and fluorescence intensity. J. Clin. Lab. Anal. 5, 255-261.

Wellinghausen, N., Kirchner, H., Rink, L., 1997. The immunobiology of zinc. Immunol. Today 18, 519-521.

Whitacre, C.C., Reingold, S.C., O'Looney, P.A., 1999. A gender gap in autoimmunity. Science 283, 1277-1278.

Yanai, M., Sato, K., Aoki, N., Takiyama, Y., Oikawa, K., Kobayashi, H., Kimura, S. Harabuchi, Y., Tateno, M. 2007. The role of CCL22/macrophage-derived chemokine in allergic rhinitis. Clin. Immunol. doi:10.1016/j.clim.2007.08.002. 


\section{Legends to figures:}

Figure 1: TH2/TH1 ratio in healthy old and nonagenarians.

The TH2/ TH1 ratio was analyzed using appropriate CCR and CD3 as markers on peripheral blood lymphocytes from 60 healthy old subjects and 15 healthy nonagenarians and compared to healthy young donors $(n=11)$. A reduced change in the CCR4/CCR5 ratio was observed in the old group compared to young subjects $(* \mathrm{p}=0.026)$ and nonagenarians $(* \mathrm{p}=0.012)$. Significances were calculated by the Wilcoxon test, two-sided $($ mean $\pm \mathrm{SE})$.

Figure 2: Comparison of CCR4 and CCR5 expression on $\mathrm{T}$ cells before and after zinc supplementation. Immunophenotypic characterization of CCR4 and CCR5 positive T cells before and after zinc supplementation by FACS analysis displayed by representative dot plots. Two-colour fluorescence staining of lymphocytes from thawed (A) or fresh blood (B) samples are shown. 15000 cells were measured and gated on lymphocytes.

Figure 3: Effect of zinc adjustment to CCR4/CCR5 ratios TH2 cells of frozen samples and whole blood cells from elderly donors.

The TH2/TH1 ratio was analyzed using their appropriate CCR and CD3 as markers on thawed peripheral blood lymphocytes (gray bars; $n=15$, mean \pm SE) and on whole blood (black bars; $n=18$, mean \pm SE) from healthy elderly subjects before and after seven weeks of zinc supplementation. A slight increase in the CCR4/CCR5 ratio after zinc supplementation was observed in the frozen samples whereas a slight decrease in the CCR4/CCR5 ratio in whole blood samples was detected by FACS analysis. 


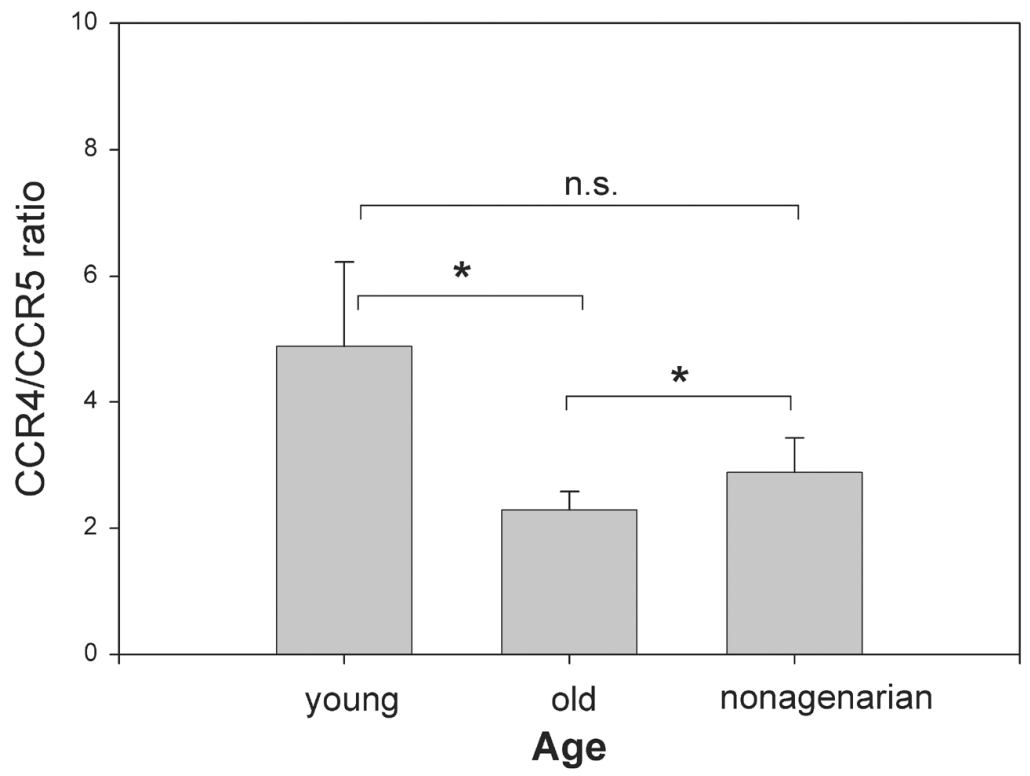

Fig.1
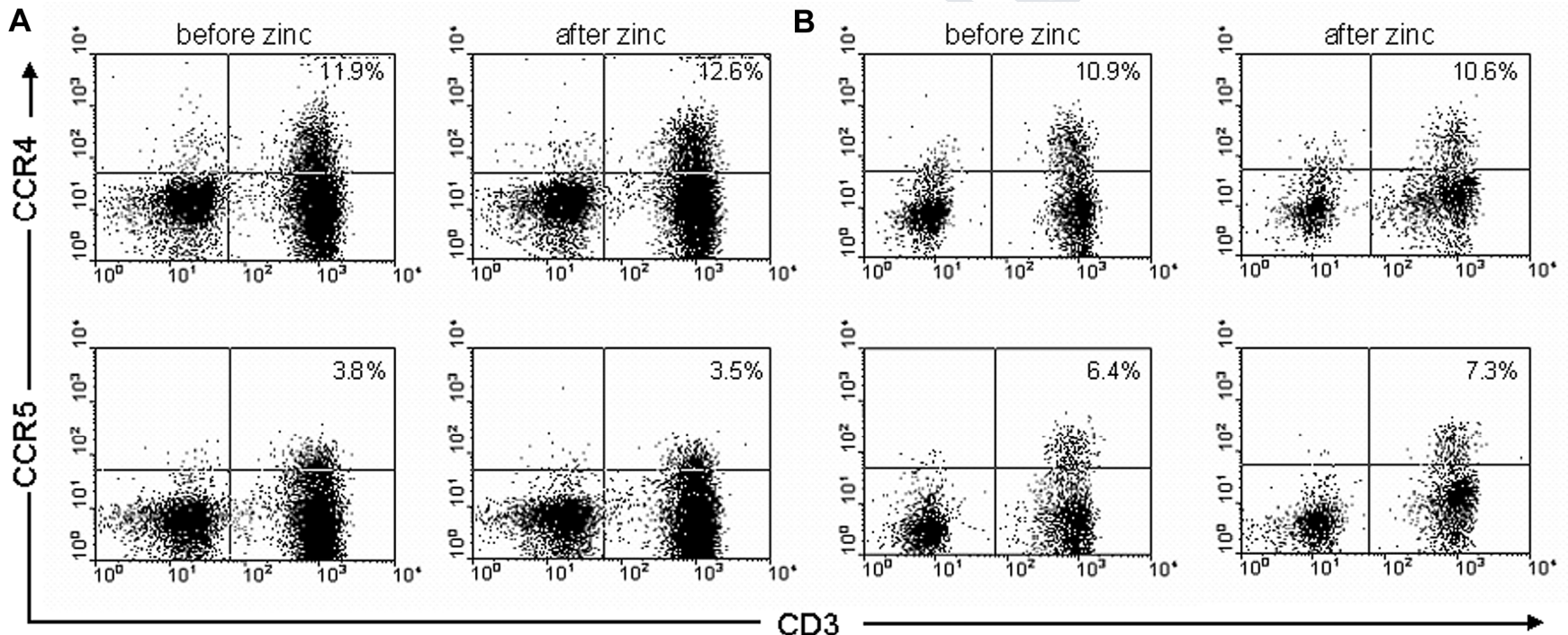

Fig.2 


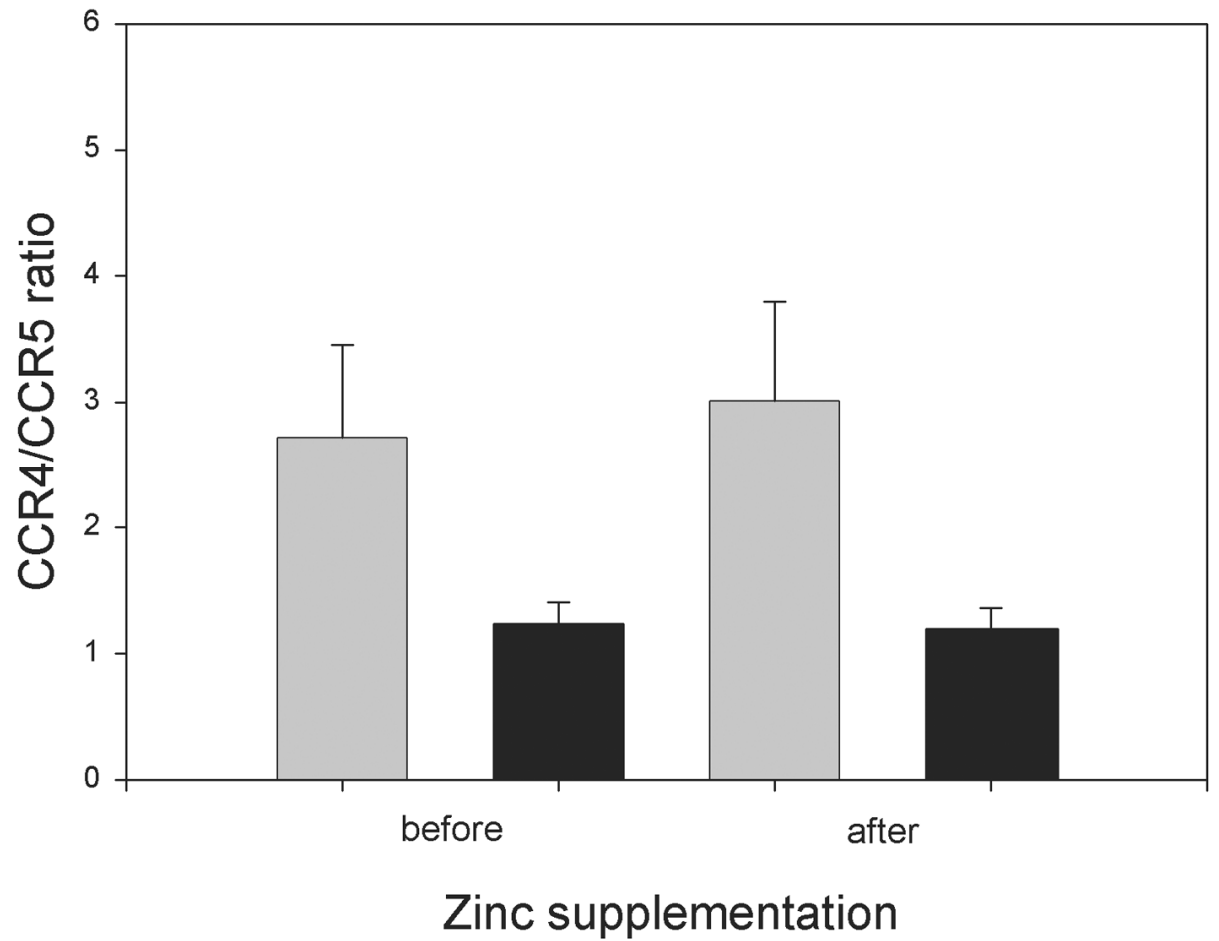

Fig.3 